\title{
Multistage Stochastic Decision and Economic Processes ${ }^{\#}$
}

\author{
Vlasta Kaňková" \\ Introduction
}

Multistage (say $M$-stage; $M$ 2) stochastic programming problems correspond to many economic activities (with a random element) that can be reasonably considered with respect to some finite „discrete“ (say $(1, M))$ time interval and simultaneously there exists a possibility to decompose them with respect to the individual time points. An unneglected random element is connected with the multistage stochastic programming problem and the control of the corresponding activity is assumed to be suitable with respect to the mathematical expectation of the objective function; the constraints set can depend on the corresponding probability measure. The multistage stochastic programming problems correspond to the situations that can be decomposed with respect to the individual time points at which a decision must be taken. The decision at the individual time point, say $k$, can depend only on the random elements realisations and the decisions to the time point $k-1$ (we say that it must be nonanticipative).

To introduce a mathematical definition of the multistage (say $M$-stage; $M 2$ ), generally nonlinear, stochastic programming problem let $\xi^{j}, j=1, \ldots, M$ denote an $s$-dimensional random vector; $F^{\xi^{j}}\left(z^{j}\right), z^{j} \in R^{s}, j=1,2, \ldots, M$ denote the distribution function of the $\xi^{j}$ and $F^{\xi^{k} \mid \bar{\xi}^{k-1}}\left(z^{k} \mid \bar{z}^{k-1}\right), z^{k} \in R^{s}, \bar{z}^{k-1} \in R^{(k-1) s}, k=2, \ldots, M$ denote the conditional distribution function $\left(\xi^{k}\right.$ conditioned by $\left.\bar{\xi}^{k-1}\right) ; \bar{\xi}^{k}=\left[\xi^{1}, \ldots, \xi^{k}\right] ; \bar{z}^{k}=\left[z^{1}, \ldots, z^{k}\right], z^{j} \in R^{s}$; $Z_{F_{6}}^{j} \subset R^{s}, j=1,2, \ldots, M$ denote the support of the probability measure corresponding to $F^{\xi^{j}}\left(z^{j}\right)$.

Let, furthermore, $g_{0}^{M}\left(\bar{x}^{M}, \bar{z}^{M}\right)$ be a continuous function defined on $R^{n M} \times R^{s M}$; $X^{k} \subset R^{n}, \quad k=1,2, \ldots, M$ be a nonempty set; $K_{F}^{k+1}\left(\bar{x}^{k}, \bar{z}^{k}\right), \quad k=1, \ldots, M-1$ be a multifunction mapping $R^{n k} \times R^{s k}$ into the space of subsets of $R^{n}$. $\bar{x}^{k}=\left[x^{1}, \ldots, x^{k}\right], x^{j} \in R^{n} ; \quad \bar{X}^{k}=X^{1} \times X^{2} \ldots \times X^{k} ; \quad \bar{Z}_{F}^{k}=Z_{F}^{1} \times Z_{F}^{2} \ldots \times Z_{F}^{k}, \quad j=1, \ldots, k$, $k=1,2, \ldots, M .\left(R^{n}, n \geq 1\right.$ denotes an $n$-dimensional Euclidean space.) See that the multifunctions $K_{F}^{k+1}\left(\bar{x}^{k}, \bar{z}^{k}\right)=\underset{F^{\xi^{k}} \mid \bar{F}^{k-1}}{k+1}\left(\bar{x}^{k}, \bar{z}^{k}\right), k=1, \ldots, M-1$ can
generally depend on the system $F$ defined by

$$
F=\left\{F^{\xi^{1}}, F^{\xi^{2} \mid \xi^{1}}, \ldots, F^{\xi^{M} \mid F^{M-1}}\right\}
$$

\footnotetext{
\# $\quad$ This research was supported by the Czech Science Foundation under grants 402/04/1294, 402/02/1015 and the Grant Agency of the Academy of Sciences of the Czech republic under grant A 7075202.

* RNDr. Vlasta Kaňková, CSc. - research fellow; Department of Econometrics, Institute of Information Theory and Automation of the Academy of Sciences of the Czech Republic, Pod Vodárenskou věží 4, 18208 Prague 8, Czech Republic; <kankova@utia.cas.cz>.
} 
A general $M$-stage stochastic programming problem (M 2) can be introduced (see e.g. Birge (1997), Dupačová (1995), King (1988) or Prékopa (1995)) in the form:

Find

$$
\varphi(F)=\inf \left\{\mathrm{E}_{F^{\xi^{1}}} g_{F}^{1}\left(x^{1}, \xi^{1}\right) \mid x^{1} \in X^{1}\right\}
$$

where the function is defined recursively

$$
\begin{aligned}
& g_{F}^{k}\left(\bar{x}^{k}, \bar{z}^{k}\right)=\inf \left\{\mathrm{E}_{F^{\xi^{k+1} \mid \bar{\xi}^{k}=\bar{z}^{k}}} g_{F}^{k+1}\left(\bar{x}^{k+1}, \bar{\xi}^{k+1}\right) \mid x^{k+1} \in K_{F}^{k+1}\left(\bar{x}^{k}, \bar{z}^{k}\right)\right\}, k=1, \ldots, M-1, \\
& g_{F}^{M}\left(\bar{x}^{M}, \bar{z}^{M}\right):=g_{0}^{M}\left(\bar{x}^{M}, \bar{z}^{M}\right) .
\end{aligned}
$$

$\mathrm{E}_{F^{\xi^{1}}}, \mathrm{E}_{F^{\xi^{k+1} \mid \xi^{k}=\bar{z}^{k}}}, k=1, \ldots, M-1$ denote the operators of mathematical expectation corresponding to $F^{\xi^{1}}(\cdot), F^{\xi^{k+1} \mid \bar{\xi}^{k}}\left(\cdot \mid \bar{z}^{k}\right)$. The problems determined by the relations (3) are parametric problems and can be considered as the inner optimization problems connected with the stages $k+1, k=1, \ldots, M-1$.

Remark. Some symbols in (2) and (3) (generally) may not be well-defined. In this paper, we neglect this situation and, consequently, we suppose that the problem is well-defined.

In the stochastic programming literature, examples of multistage stochastic programming applications can be found. We can recall the applications in banking and financial mathematics (see e.g. Dupačová - Hurt - Štěpán (2002)); power capacity generation planning Nowak - Römisch (2000) or the application to unemployment problem and restructuralization (see e.g. Chovanec (2004)). Some other applications can be found in Prékopa (1995).

\section{Multiobjective and Multistage Stochastic Programming Problems}

In the "classical" applications mostly $K_{F}^{k+1}\left(\bar{x}^{k}, \bar{z}^{k}\right), k=1, \ldots, M-1$ can be introduced in the form

$$
K_{F}^{k+1}\left(\bar{x}^{k}, \bar{z}^{k}\right)=\left\{x^{k+1} \in X^{k+1}: g_{i}^{k+1}\left(\bar{x}^{k+1}, \bar{z}^{k}\right) \leq 0, i=1, \ldots, \bar{l}_{k+1}\right\},
$$

where $g_{i}^{k+1}\left(\bar{x}^{k+1}, \bar{z}^{k}\right), i=1,2, \ldots, \bar{l}_{k+1}$ are continuous functions defined on $R^{n(k+1)} \times R^{s k}$. However, the general case when $K_{F}^{k+1}\left(\bar{x}^{k}, \bar{z}^{k}\right)$ depends on $F$ corresponds to many economic problems too (see e.g. Chovanec (2004) or Prékopa (1995)). Moreover, it can happen also that the original (,underlying“) problem with random element is multiobjective one and the corresponding ,deterministic“ problem is a stochastic (may be multiobjective) programming problem with probability constraints (for the definition see e.g. Kaňková (1999a), Prékopa (1995)).

To explain this case, let us first consider one-stage original „underlying“ problem with random elements in the form of the multiobjective problem (see e.g. Kaňková (1995a), Prékopa (1995)):

Find 
$\min g_{i}(x, \zeta), i=1,2, \ldots, l_{1} \quad$ subject to $x \in X$ such that $g_{i}(x, \zeta) \oplus, i=l_{1}+1, \ldots, l$,

$g_{i}(x, \zeta), i=1, \ldots, l$ are functions defined on $R^{n} \times R^{s}, X \subset R^{n}$ is a nonempty set, $\zeta$ is an $s$-dimensional random vector. To recall a philosophy e.g. Kaňková (1999a) we assume: 1 古亩,

A.1. It is ,reasonable“ to prefer a few of the objective functions, say $\mathrm{g}_{i}(x, \zeta), i=1, \ldots, l_{2}$,

A.2. there exist real-valued constants $k_{l_{2}+1}, \ldots, k_{l_{1}}$ (known from the literature as aspiration levels) such that the fulfilling of the relations

$$
g_{i}(x, \zeta) \mathrm{k}_{i}, i=l_{2}+1, \ldots, l_{1}, x \in X \text { is "very" acceptable, }
$$

A.3. under the assumptions A.1. and A.2. the problem defined by (5) can be replaced by the following multiobjective problem:

Find

$\min g_{i}(x, \zeta), i=1,2, \ldots, l_{2} \quad$ subject to $x \in X$ such that $\hat{g}_{i}(x, \zeta) \leq 0, i=l_{2}+1, \ldots, l$,

where

$$
\begin{aligned}
& \hat{g}_{i}(x, z)=g_{i}(x, z)-k_{i}, \quad i=l_{2}+1, \ldots, l_{1}, \quad x \in R^{n}, \quad z \in R^{S}, \\
& \hat{g}_{i}(x, z)=g_{i}(x, z), \quad i=l_{1}+1, \ldots, l, \quad x \in R^{n}, \quad z \in R^{S} .
\end{aligned}
$$

Assuming that $x$ must be determined before the realization of the random element, under the assumptions A.1, A.2 and A.3 the following multiobjective problems can be „reasonable“ in many applications:

\section{P.1. Find}

$$
\begin{aligned}
& \inf \mathrm{E}_{F^{\xi}} g_{i}(x, \zeta), i=1,2, \ldots, l_{2} \quad \text { subject to } x \in \bar{X}_{F^{\xi}}(\bar{\alpha}), \\
& \text { where } \bar{X}_{F^{\xi}}(\bar{\alpha})=\cap_{i=l_{2}+1}^{l} \bar{X}_{F^{\xi}}^{i}\left(\alpha_{i}\right), \\
& \bar{X}_{F^{\xi}}^{i}\left(\alpha_{i}\right)=\left\{x \in X: P_{F^{\xi}}\left\{\hat{g}_{i}(x, \zeta) \leq 0\right\} \geq \alpha_{i}\right\}, i=l_{2}+1, \ldots, l .
\end{aligned}
$$

\section{P.2. Find}

$$
\begin{aligned}
& \operatorname{infE}_{F^{\xi}} g_{i}(x, \xi), i=1,2, \ldots, l_{2} \quad \text { subject to } x \in X_{F^{\xi}}(\alpha), \\
& \text { where } \quad X_{F^{\xi}}(\alpha)=\left\{x \in X: P_{F^{\xi}}\left\{\hat{g}_{i}(x, \xi) \leq 0, \quad i=l_{2}+1, \ldots, l\right\} \geq \alpha\right\} .
\end{aligned}
$$

$\bar{\alpha}=\left(\alpha_{l_{2}+1}, \ldots, \alpha_{l}\right), \alpha_{i} \in\langle 0,1\rangle, i=l_{2}+1, \ldots, l ; \alpha \in\langle 0,1\rangle ;$ the symbol $F^{\xi}(z)$ denotes the distribution function corresponding to $\zeta$.

The problems introduced by (8) and (9) are mutiobjective stochastic programming problems. If $l_{2}=1$, then we obtain special cases; in details we obtain one-objective stochastic programming problems with the individual and joint probability constraints. Evidently, the above mentioned approach can be also employed in the multistage case to obtain the multistage stochastic programming problems with the individual or joint probability constraints. It is easy to see that the problems with joint probability constraints are rather more complicated. A relationship, between the above mentioned two problems, can be found in Kaňková (1999b) or Prékopa (1995). 
Furthermore, we assume that $l-l_{2}=s$ and, moreover, that there exist functions $h_{i}(x), i=l_{2}+1, \ldots, l$ defined on $R^{n}$ such that

$$
\hat{g}_{i}(x, z)=h_{i}(x)-\zeta_{i}, \quad i=l_{2}+1, \ldots, l, \quad x \in R^{n}, \quad \xi=\left(\xi_{l_{2}+1}, \ldots, \zeta_{l}\right) .
$$

It is known from the stochastic programming literature (see e.g. Kaňková (1997)) that, under the validity of the relation (10), for every $i \in\left\{l_{2}+1, \ldots, l\right\}$ and $\alpha_{i} \in(0,1)$

$$
x \in \bar{X}_{F^{\xi}}^{i}\left(\alpha_{i}\right) \Leftrightarrow x \in X \text { and simultaneously } h_{i}(x) \leq k_{F_{i}^{\xi}}\left(\alpha_{i}\right),
$$

where $F_{i}^{\zeta}, i=l_{2}+1, \ldots, l$ denotes one-dimensional marginal distribution function corresponding to $F^{\zeta}$ and $k_{F^{\zeta}}\left(\alpha_{i}\right)$ is defined by the relations

$$
k_{F_{i}^{\xi}}\left(\alpha_{i}\right)=\sup \left\{z \in R^{s}: P_{F_{i}^{\xi}}\left\{\zeta_{i}: z_{i} \leq \zeta_{i}\right\} \geq \alpha_{i}, \quad i=l_{2}+1, \ldots, l .\right.
$$

Consequently, under the assumptions of this section the problem (8) can be replaced by the following one:

Find

$$
\inf _{F^{\zeta}} g_{i}(x, \zeta), i=1,2, \ldots, l_{2} \text { subject to } x \in X \text { such that } h_{i}(x) \leq k_{F_{i}^{\zeta}}\left(\alpha_{i}\right), i=l_{2}+1, \ldots, l .(12
$$

In the case $l_{2}=1$ the last problem is one-stage stochastic programming problem with "deterministic" constraints. Of course this approach can be employed in the multistage case too. We restrict our consideration (in this paper) to the case $l_{2}=1$.

\section{Problem Analysis}

Evidently the multistage stochastic programming problems introduced by the relations (2) and (3) are rather complicated optimization problems. A great attention has been paid (in the stochastic programming literature) to get suitable approximate solution algorithms. However this effort has been mostly successful only in the linear case and, moreover, when the relation (4) is fulfilled. To construct (generally) a solution algorithm mostly, first, the system $F$ is replaced by another one, that corresponds to an approximate probability measure with final support. The new problem is then one-stage problem of large dimensions that can be mostly again solved only approximately (for more details see e.g. Birge - Louveaux (1997), Birge (1988), Dupačová - Hurt - Štěpán (2002), Kaňková Šmíd (2004), Prékopa (1995), Ruzczyński (2003), Šmíd (2003)).

Employing the above mentioned approach, a solution error is a composition of two parts. In more details, if we replace in (2), (3) the system $F$ by another one

$$
G=\left\{G^{\xi^{1}}\left(z^{1}\right), G^{\left.\xi^{k}\right|^{-k-1}}\left(z^{k} \mid \bar{z}^{k-1}\right), z^{k} \in R^{s}, \bar{z}^{k-1} \in R^{(k-1) s}, k=2, \ldots, M\right\},
$$

we obtain a new multistage problem with the optimal value $\varphi(G)$. Evidently the corresponding error can be measured by the value $\mid \varphi(F)-\varphi(G)$. The second component of the error is caused by a numerical inaccuracy. To estimate the value $|\varphi(F)-\varphi(G)|$ we employ the triangular inequality to obtain successively: 


$$
\begin{aligned}
& \mathrm{E}_{F^{\xi^{1}}} g_{F}^{1}\left(x^{1}, \xi^{1}\right)-\mathrm{E}_{G^{\xi^{1}}} g_{G}^{1}\left(x^{1}, \xi^{1}\right) \mid \leq \\
& \left|\mathrm{E}_{F^{\xi^{1}}} \inf _{x^{2} \in K_{F}^{2}\left(x^{1}, \xi^{1}\right)} \mathrm{E}_{F^{\xi^{2}} \xi^{1}} g_{F}^{2}\left(\bar{x}^{2}, \bar{\xi}^{2}\right)-\mathrm{E}_{G^{\xi^{1}}} \inf _{x^{2} \in K_{F}^{2}\left(x^{1}, \xi^{1}\right)} \mathrm{E}_{F^{\xi^{2}} \mid \xi^{1}} g_{F}^{2}\left(\bar{x}^{2}, \bar{\xi}^{2}\right)\right|+ \\
& \mid \mathrm{E}_{G^{\xi^{1}}} \inf _{x^{2} \in K_{F}^{2}\left(x^{1}, \xi^{1}\right)} \mathrm{E} \inf _{G^{\xi^{2}} \mid \xi^{1}} \inf _{x^{3} \in K_{F}^{3}\left(\bar{x}^{2}, \bar{\xi}^{2}\right)} \mathrm{E}_{F^{\xi^{3}} \mid \xi^{2}} g_{F}^{3}\left(\bar{x}^{3}, \bar{\xi}^{3}\right)- \\
& \mathrm{E}_{G^{\xi^{1}}} \inf _{x^{2} \in K_{G}^{2}\left(x^{1}, \xi^{1}\right)} \mathrm{E} \operatorname{Enf}_{G^{\xi^{2} \mid \xi^{1}}} \inf _{x^{3} \in K_{F}^{3}\left(\bar{x}^{2}, \bar{\xi}^{2}\right)} \mathrm{E} F_{\xi^{3} \xi^{2}} g_{F}^{3}\left(\bar{x}^{3}, \bar{\xi}^{3}\right) \mid+ \\
& \mid \mathrm{E}_{G^{\xi^{1}}} \inf _{x^{2} \in K_{F}^{2}\left(x^{1}, \bar{\xi}^{1}\right)} \ldots \inf _{x^{M-1} \in K_{G}^{M-1}\left(\bar{x}^{M-2}, \bar{\xi}^{M-2}\right)} \mathrm{E}_{G^{\xi^{M-1} \mid \xi^{M-2}}} \inf _{x^{M} \in K_{F}^{M}\left(\bar{x}^{M-1}, \bar{\xi}^{M-1}\right)} \mathrm{E}_{\left.F^{\xi^{M}}\right|^{M-1}} g_{F}^{M}\left(\bar{x}^{M}, \bar{\xi}^{M}\right)- \\
& \left.\mathrm{E}_{G^{\xi^{1}}} \inf _{x^{2} \in K_{G}^{2}\left(x^{1}, \xi^{1}\right)} \ldots \inf _{x_{G}^{M-1} \in K_{G}^{M-1}\left(\bar{x}^{M-2}, \bar{\xi}^{M-2}\right)} \mathrm{E} \operatorname{linf}_{\xi^{M-1} \mid \xi^{M-2}} \inf _{x^{M} \in K_{G}^{M}\left(\bar{x}^{M-1}, \bar{\xi}^{M-1}\right)} \mathrm{E}{ }_{G^{\xi^{M}}}\right|_{\xi^{M-1}} g_{G}^{M}\left(\bar{x}^{M}, \bar{\xi}^{M}\right) \mid
\end{aligned}
$$

for every $x^{1} \in X^{1}$.

It follows from the last relation that the difference

$$
|\varphi(F)-\varphi(G)|
$$

depends on the corresponding differences for one-stage decomposed parametric problems (3). Consequently, the results achieved for one-stage problems can be employed to the multistage case. This approach has been employed in Kaňková (2002a), Kaňková (2002b) and Kaňková - Šmíd (2004). According, to the above introduced inequality, the system $G$ must be „near" to $F$ and, simultaneously, the problem (3), (4) must be stable w.r.t probability measure space. Of course, the approximate system $G$ can be deterministic or stochastic. To introduce the corresponding results a restriction to Markov type of dependence has been done.

\section{Multistage Stochastic Programs and Markov Dependence}

To present the corresponding results we assume:

D.1. There exist $s-$ dimensional random vectors $\xi^{0}, \eta$ and a continuous vector function $f\left(z^{2}, z^{1}\right)$ defined on $R^{s} \times R^{s}$ such that

- $F^{\xi^{1}}\left(z^{1}\right)=F^{\xi^{1} \xi^{0}}\left(z^{1} \mid z^{0}\right)$ for every $z^{1} \in Z_{F}^{1}$ and (known value) $z^{0} \in Z_{F}^{0}$,

- $\quad F^{\xi^{k} \bar{\xi}^{k-1}}\left(z^{k} \mid \bar{z}^{k-1}\right)=F^{\eta}\left(f\left(z^{k}, z^{k-1}\right)\right), k=1, \ldots, M$ for every $\bar{z}^{k} \in \bar{Z}_{F}^{k}$.

The symbol $F^{\eta}(\cdot)$ denotes the distribution function corresponding to $\eta ; Z_{F}^{0}=\bar{Z}_{F}^{0}$ denotes the support of the probability measure corresponding to the random vector $\xi^{0}$; the symbol $F^{\xi^{1} \mid \xi^{0}}\left(z^{1} \mid z^{0}\right)$ is reserved for the conditional distribution function.

If $F_{N}^{\eta}(\cdot)$ denotes the empirical distribution function determined by an independent random sample $\left\{\eta^{i}\right\}_{i=-N}^{-1}$ corresponding to $F^{\eta}(\cdot)$, then

$$
F(N)=\left\{F_{N}^{\eta}\left(f\left(z^{1}, z^{0}\right)\right), F_{N}^{\eta}\left(f\left(z^{k}, z^{k-1}\right), k=2, \ldots, M\right\}\right.
$$


estimates the system $F$. Consequently, replacing the system (4) by the system (16) we obtain an approximating problem to the multistage problem introduced by (2) and (3). We denote its optimal value by the symbol $\varphi(F(N))$.

The assumptions under which

$$
P\left\{|\varphi(F)-\varphi(F(N))| \rightarrow_{(N \rightarrow+\infty)} 0\right\}=1 .
$$

are introduced in Kaňková (2002a). If, moreover,

D.2. for every $\bar{z}^{k} \in \bar{Z}_{F}^{k}, u \in Z_{F^{\eta}}$ there exists just one $z^{k+1} \in Z_{F}^{k+1}$ such that

$$
u=f\left(z^{k+1}, z^{k}\right) \text {, }
$$

then in Kaňková (2002a) and Kaňková (2002b) the assumptions were introduced under which for every $t>0, N=1.2, \ldots$

$$
P\{|\varphi(F)-\varphi(F(N))|>t\} \leq \exp \left\{-\frac{N t^{2}}{18 M^{2} H^{2}}\right\} \sum_{k=0}^{M-1} m^{k+1}\left(X^{k+1}, \frac{t}{3 M}\right)
$$

where $m^{k+1}\left(X^{k+1}, \frac{t}{3 M}\right), k=0, \ldots, M-1$ are constants depending on the sets $X^{k+1}$, the value $t>0$ and the individual objective functions $g_{i}^{k+1}\left(\bar{x}^{k+1}, \bar{z}^{k}\right) . Z_{F^{\eta}}$ denotes the support corresponding to $F^{\eta}(u), H$ is a constant.

To deal with a deterministic approximation $G$ we assume:

D.3. There exist $s$-dimensional random sequence $\left\{\eta^{k}\right\}_{k=-\infty}^{+\infty}$ and a matrix $A$ of the type $(s \times s)$ such that

- $\left\{\eta^{k}\right\}_{k=-\infty}^{+\infty}$ is a sequence of independent $s$-dimensional, identically distributed random vectors.

- $\xi^{k}=A \xi^{k-1}+\eta^{k}, \quad k=\ldots,-1,0,1, \ldots$,

and, moreover, we recall the definition of the Wasserstein metric $d_{W_{1}}(\cdot$,$) in the space of$ $s$-dimensional probability measures, especially in the space

$$
M_{1}\left(R^{s}\right)=\left\{v \in P\left(R^{s}\right): \int_{R^{s}}\|z\| v(d z)<+\infty\right\}
$$

$P\left(R^{s}\right)$ denotes the set of all (Borel) probability measures in $R^{s}$ and $\|\cdot\|$ denotes the Euclidean norm in $R^{s}$. The Wasserstein metric $d_{W_{1}}(\cdot)$ can be defined by

$$
d_{W_{1}}(\mu, v)=\inf \left\{\int_{R^{s} \times R^{s}}\|z-\bar{z}\| \kappa(d z \cdot d \bar{z}): \kappa \in D(\mu, v)\right\}, \quad v, \mu \in M\left(R^{s}\right) .
$$

$D(\mu, v)$ is the set of those probability measures in $P\left(R^{s} \times R^{s}\right)$ whose marginal distribution are $\mu$ and $\nu$.

Of course if we replace in D.1 the distribution function $F^{\eta}$ by another one $G^{\eta}$, then we obtain another system $G$ instead of $F$. An assumptions under which there exists a constant $C$ such that

$$
|\varphi(F)-\varphi(G)| \leq C d_{W_{1}}\left(P_{F^{\eta}}, P_{G^{\eta}}\right)
$$


were introduced Kaňková (2002b); the similar results with $L_{1}$ norm are introduced in Kaňková - Šmíd (2004).

Remark. The paper Šmíd (2003) deals with similar approximation without assumption on the Markov dependence.

\section{Conclusion}

The aim of the paper was to present a brief survey of the multistage stochastic programming programs. In particular, the aim of the paper was to explain the base of the problem, to introduce a suitable mathematical definition, to recall some applications known from the literature as well as to mention numerical solution possibilities.

To this end the multistage stochastic programming problem has been introduced in the nonlinear (rather general) setting. Namely, many economic processes correspond to nonlinear models (see e.g. Markowitz model of portfolio selection, Dupačová - Hurt Štěpán (2002) or the models of unemployment introduced in Chovanec (2004) and Kaňková (1999b). Of course, in the literature, first, the linear models were introduced and investigated. The linear models with finite probability support are equivalent to linear one-stage (of course a large dimension) programming problems. Consequently, the linear models with general probability measure support can be solved approximately by linear programming problems too (see e.g. Birge - Louveaux (1997), Birge (1998) and Dupačová - Hurt - Štěpán (2002). However, in spite of this fact to solve numerically linear models corresponding to applications can be (from the numerical point of view) very complicated.

To solve exactly the nonlinrar models is mostly impossible. Consequently, some approximate solution schemes have been constructed (see e.g. Šmíd (2003)). These approximative schemes can be deterministic as well as stochastic. The stochastic approach gives the possibilities to construct the approximate schemes based on the empirical data even in the cases when the theoretical measure is completely unknown. In the case when the random element fulfils the Markov type of dependence, the approximate scheme can be constructed on the base of one realization of the random sequence. The paper restricts just to this special case. Moreover, in the paper, the approximate schemes were considered only under the assumption that the constraints set does not depend on the probability measure.

Of course, the corresponding assumptions have to be fulfilled (for more details see e.g. Kaňková (1998) or Kaňková - Šmíd (2004)). However, it is over the possibilities of this paper to include, in our consideration, all based situations leading (from the mathematical point of view) to the multistage programs. Moreover, many problems about these complicated optimization models still wait not only for the solution, however first, for a good analysis and discussion.

\section{References}

[1] BIRGE, J. R. - LOUVEAUX, F. (1997): Introduction to Stochastic Programming. Berlin, Springer, 1997. 
[2] BIRGE, J. R. (1988): An L-Shaped Method Computer Code for Multistage Stochastic Linear Programs. In. Ermoliev, Y. and Wets, R. J. B. (eds.): Numerical Techniques for Stochastic Optimization Problems. Berlin, Springer, 1988, pp. 237-254.

[3] DUPAČOVÁ, J. (1995): Multistage Stochastic Programs: the State-of-the-Art and Selected Bibliography. Kybernetika, 1995, Vol. 31, No. 2, pp. 151-174.

[4] DUPAČOVÁ, J. - HURT, J. - ŠTĚPÁN, J. (2002): Stochastic Modelling in Economics and Finance. Dordrecht, Kluwer, 2002.

[5] CHOVANEC, P. (2004): Multistage Stochastic Programming Problems - Application to Unemployment Problem and Restructuralization (Diploma work in Czech) Prague, MFF UK, 2004.

[6] KAŇKOVÁ, V. (1997): On the Stability in Stochastic programming: the Case of Individual probability Constraints. Kybernetika, 1997, Vol. 33, No. 5, pp. 525-546.

[7] KAŇKOVÁ, V. (1998): A Note on Multistage Stochastic Programming. In. Proceedings $11^{\text {th }}$ joint Czech-Germany-Slovak Conference. Liberec (Czech Republic), University of Technology, pp. 45-52.

[8] KAŇKOVÁ, V. (1999a): A Note of Analysis of Economic Activities with Random Elements. In. M. Plevný, M. - Friedlich, V. (eds.): Proceedings of the Mathematical Methods in Economics 1998. Cheb, University of West Bohemia, Czech Society for Operations Research, 1999, pp. 53-58.

[9] KAŇKOVÁ, V. (1999b): Unemployment Problem, Reatructuralization and Stochastic Programming. In. Plešinger, J. (ed.): Proceedings of the Mathematical Methods in Economics 1999. Jindřichův Hradec, Czech Society for Operations Research, 1999, pp. 151-158.

[10] KAŇKOVÁ, V. (2002a): A Remark on Empirical Estimates in Multistage Stochastic Programming. . Bulletin of the Czech Economic Society, 2002, Vol 17, pp. 32-51.

[11] KAŇKOVÁ, V. (2002b): A Remark on the Analysis of Multistage Stochastic Programs: Markov dependence. Zeitschrift für Angewandte Mathematik und Mechanik, 2002, Vol. 82, No. 11-12, pp. 781-793.

[12] KAŇKOVÁ, V. - ŠMÍD, M. (2004): A Remark on Approximation in Multistage Stochastic Programming; Markov Dependence. Kybernetika , 2004, Vol. 40, No. 5, pp. 625-638.

[13] KING, A. J. (1988): Stochastic Programming Problems: Examples from the Literature. In: Ermoliev, Y. - Wets, R. J.-B. (eds.): Numerical Techniques for Stochastic Optimization Problems. Berlin, Springer, 1988, pp. 543-567.

[14] NOWAK, M. - RÖMISCH, W. (2000): Stochastic Lagrangian Relaxation Applied to Power Scheduling in Hydro-Termal System Under Uncertainty. Annals of Operation Research, 2000. Vol. 100, pp. 251-272.

[15] PRÉKOPA, A. (1995): Stochastic Programming. Budapest, Akadémiai Kiadó and Dordrecht, Kluwer, 1995.

[16] RUSZCZYŃSKI, A. (2003): Decomposition Methods. In. Ruszczyński, A. - Shapiro, A. (eds.): Stochastic Programming, Handbooks in Operations Research and Management Science, Vol. 10. Amsterdam, Elsevier, 2003, pp. 141-209.

[17] ŠMÍD, M. (2003): Notes on Approximate Computation of Expectation (Research Report). Prague, UTIA AS CR, 2003. 


\title{
Vícestupňové stochastické rozhodování a ekonomické procesy
}

\section{Vlasta Kaňková}

\begin{abstract}
Abstrakt
Všeobecně je známo, že ekonomické procesy se vyvíjejí v čase, jsou ovlivňovány náhodným faktorem a navíc velmi často je vhodné jejich současné ohodnocení několika účelovými funkcemi. Matematické teorie vícestupňového stochastického programování, řízených Markovových procesů, empirických procesů stejně jako teorie vícekriteriálního stochastického programování mohou být využity pro optimální (nebo alespoň vhodný) zásah do původního procesu. Práce je zaměřena na př́ípad vícestupňového stochastického programování s Markovovou závislostí.
\end{abstract}

Klíčová slova: ekonomické procesy; vícestupňové stochastické programování; Markovova závislost.

\section{Multistage Stochastic Decision and Economic Processes}

\begin{abstract}
Economic and social phenomena develop over time, they are mostly influenced by random factors and, moreover, it is very often necessary to evaluate them simultaneously by several "objective" functions. Multistage stochastic programming problems, control Markov chains, empirical processes as well as stochastic multiobjective problems can serve to model them. We focus to cases that can be treated by multistage stochastic programming models with Markov type of dependence.
\end{abstract}

Key words: economic processes; multistage stochastic programming; Markov dependence.

JEL classification: $\mathrm{C} 44$ 